\title{
Simpler tests for immune cells could transform AIDS care in Africa
}

Over the past decade, access to costly AIDS drugs in the developing world has expanded dramatically. But deciding who could most benefit from those drugs hasn't become much easier.

Simpler, cheaper versions of the test that can indicate when an HIV-positive individual needs treatment could bring quality HIV care to even the remotest parts of Africa. Academic researchers, industry and nonprofits are all developing new tests, at least seven of which are already in use, with six more in various stages of development.

In richer countries, doctors determine who is in need of antiretroviral drugs by assessing the infected individual's CD4-cell count, which reflects the health of their immune system. Those individuals with fewer than 200 CD4 cells, the immune cells that HIV destroys, need drug therapy even if they appear healthy.

CD4 cells are usually tallied by an expensive and complicated machine called a flow cytometer, a standard tool in biology labs. The bulky machines require a steady supply of electricity and highly trained technicians. "For these rural parts of sub-Saharan Africa, there's no way a flow cytometer is going to work," says Steven Reid, project manager of the CD4 Initiative, a public-private effort that aims to develop cheaper tests.

At a minimum cost of about $\$ 50,000$, the standard machine is also well beyond the reach of most developing countries. Healthcare workers instead often rely on their instincts or wait until a person is visibly sick before providing treatment.

"That completely compromises their care," Reid says. "A simple test to say, 'You need treatment [or] you don't' would be a huge step forward."

Funded by an $\$ 8.6$ million grant from the Bill \& Melinda Gates Foundation and overseen by Imperial College London, the CD4 Initiative expects to debut a simpler version of the

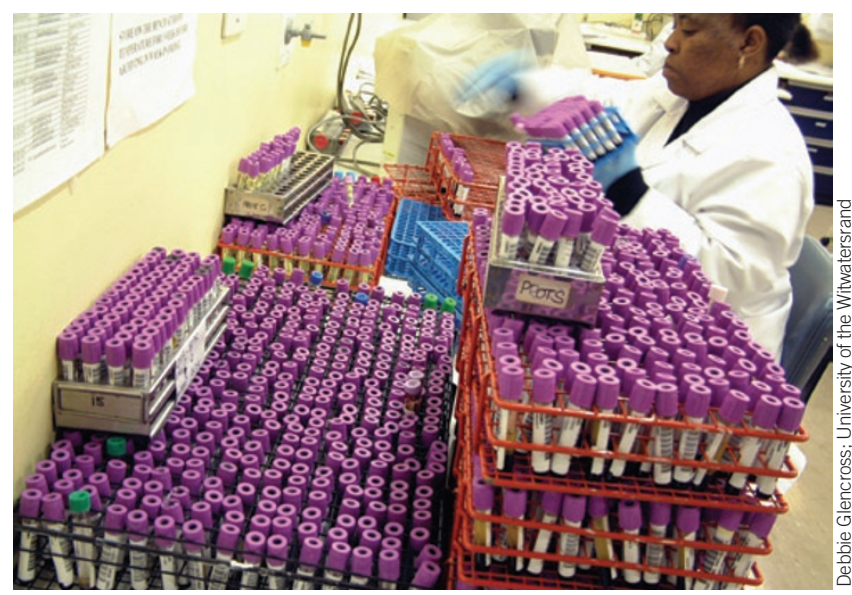

Sheer volumes: Sorting through samples to identify those in need of AIDS drugs is complicated and time-consuming.

test by 2011 that would be as easy to use as a home pregnancy test. The test would take in a drop of blood and generate a symbol—perhaps a plus or minus sign — to indicate whether an individual needs to start drug therapy.

Scientists in South Africa have also tried to simplify CD4 testing by eliminating some of the steps in the conventional tests. "[The steps] add extra cost and are really not necessary," says Debbie Glencross, a hematologist at the University of the Witwatersrand in Johannesburg.

Her shortcut slashed the cost of a test from about $\$ 80$ to $\$ 7$, prompting all 52 government
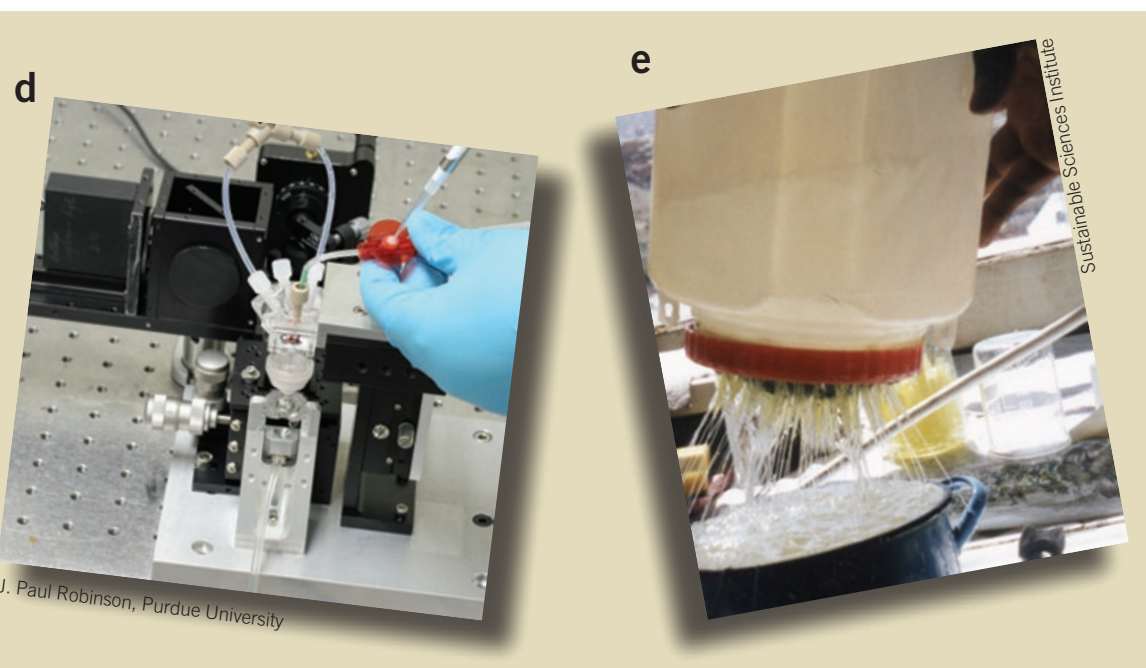

INGENIOUS INVENTIONS labs in South Africa to implement it. The new test may even be more accurate, because fewer steps leave less room for error, Glencross adds. "Even if we had all the pots of money in the world I wouldn't swap back."

Glencross's method still relies on a basic flow cytometer and a lab in which to operate it. Another model, developed by J. Paul Robinson, director of Purdue University's Cytometry Laboratories, could be used in villages that lack labs or even electricity.

Robinson's prototype is a rechargeable mini-cytometer small enough to fit in a suitcase and simple enough to be used with little training. But finding funding for its development has been difficult. Since he received an initial $\$ 250,000$ donation from Cleveland-based company Parker Hannifin, "not a single penny has come from anybody," Robinson says.

With 4.8 million people in need of antiretrovirals in sub-Saharan Africa alone, however, the potential market for a new test is enormous-and has prompted several companies to join the fray. In 2004, California-based Guava Technologies released a portable flow cytometer. That same year, $\mathrm{BD}$ Biosciences, which garnered $\$ 500$ million in cytometry-related sales last year, agreed to slash the cost of its two most basic machines by about a third in Africa and the Caribbean.

Still, these machines are out of reach for most: Guava's version sells for $\$ 35,000$ and BD's cheapest machine for $\$ 25,000$. Robinson, who operates a nonprofit called Cytometry for Life, expects to see his model cost about $\$ 5,000$. "It's truly a low-cost solution," Robinson says. "That gives me confidence that at some point someone will see the light and fund us."

Cassandra Willyard, New York 